\title{
Update of the human secretoglobin (SCGB) gene superfamily and an example of 'evolutionary bloom' of androgen- binding protein genes within the mouse Scgb gene superfamily
}

Brian C. Jackson, ${ }^{1}$ David C. Thompson, ${ }^{2}$ Mathew W. Wright, ${ }^{3}$ Monica McAndrews, ${ }^{4}$ Alfred Bernard, ${ }^{5}$ Daniel W. Nebert $6^{*}$ and Vasilis Vasiliou ${ }^{*}$

'Molecular Toxicology and Environmental Health Sciences Program, Department of Pharmaceutical Sciences, University of Colorado Anschutz Medical Center, Aurora, CO 80045, USA

${ }^{2}$ Department of Clinical Pharmacy, University of Colorado Anschutz Medical Center, Aurora, CO 80045, USA

${ }^{3}$ HUGO Gene Nomenclature Committee (HGNC), EMBL-EBI, Wellcome Trust Genome Campus, Cambridge, CB10 1SD, UK

${ }^{4}$ The Jackson Laboratory, Mouse Genome Informatics, 600 Main Street, Bar Harbor, ME 04609-1500, USA

${ }^{5}$ Unit of Toxicology and Applied Pharmacology, Catholic University of Louvain, Brussels, Belgium

${ }^{6}$ Department of Environmental Health and Center for Environmental Genetics (CEG), University of Cincinnati Medical Center, Cincinnati, OH 45267-0056, USA

*Correspondence to: Tel: +1 303724 3520(V.V); Fax: +1 303724 7266(V.V.); E-mail: vasilis.vasiliou@ucdenver.edu; dan.nebert@uc.edu

Date received (in revised form): 25th October 2011

\begin{abstract}
The secretoglobins (SCGBs) comprise a family of small, secreted proteins found in animals exclusively of mammalian lineage. There are II human SCGB genes and five pseudogenes. Interestingly, mice have 68 Scgb genes, four of which are highly orthologous to human SCGB genes; the remainder represent an 'evolutionary bloom' and make up a large gene family represented by only six counterparts in humans. SCGBs are found in high concentrations in many mammalian secretions, including fluids of the lung, lacrimal gland, salivary gland, prostate and uterus. Whereas the biological activities of most individual SCGBs have not been fully characterised, what already has been discovered suggests that this family has an important role in the modulation of inflammation, tissue repair and tumorigenesis. In mice, the large $S c g b / b$ and $S c g b 2 b$ gene families encode the androgen-binding proteins, which have been shown to play a role in mate selection. Although much has been learned about SCGBs in recent years, clearly more research remains to be done to allow a better understanding of the roles of these proteins in human health and disease. Such information is predicted to reveal valuable novel drug targets for the treatment of inflammation, as well as designing biomarkers that might identify tissue damage or cancer.
\end{abstract}

Keywords: SCGB, secretoglobin, evolutionary bloom, androgen-binding, protein, nomenclature, gene family

\section{Introduction}

The secretoglobins (SCGBs) comprise a family of secreted proteins found in mammals and marsupials. The first discovered SCGB was found in rabbits and was first called blastokinin, ${ }^{1}$ then later uteroglobin ${ }^{2}$ and is now designated SCGB1A1 (in some early literature, the SCGB family is referred to as the 'uteroglobin' family). Eventually, the term 
'secretoglobin' was coined to refer to the characteristics that all family members have in common. The 'secreto-' portion of the name indicates that these proteins are secreted. A second reason was proposed for the suffix 'globin'; their functions had largely remained a secret (Lehrer, R., personal communication). This suffix was given because secretoglobins form dimers consisting of two four- $\alpha$ helix-bundle monomers, creating a hydrophobic binding pocket, reminiscent of the globinfold, which is an eight- $\alpha$-helix bundle with a pocket for a molecule such as a heme group. ${ }^{3}$

Secretoglobins are found at high levels in many secretions, including uterine, prostatic, pulmonary, lacrimal and salivary glands, with any specific secretoglobin often being expressed in more than one tissue. For example, mRNA expression of every SCGB family member (except SCGB1D2) has been demonstrated in human airways. ${ }^{4}$ In general, the physiological and pathophysiological functions of most individual SCGBs remain to be defined. Nevertheless, roles currently ascribed to SCGBs include lung maintenance and repair, immune modulation and, at least in rodents, mate selection. Some SCGB family members, such as mammaglobin, have been successfully used as epithelial cancer biomarkers.

SCGBs are small ( $\sim 10 \mathrm{kDa}$ in humans) proteins that dimerise before secretion. Dimers are resistant to proteases, heat and $\mathrm{pH}^{5,6}$ The crystal structures of several SCGBs have been resolved, including those of rabbit and rat uteroglobin (Protein Data Bank identifiers [PDB ID]:1UTG, 2UTG, 1UTR), rat Clara-cell specific protein (CCSP) (PDB ID:1CCD) and feline $\mathrm{CH} 2$ (Feld-1) (PDB ID:1PUO, 1ZKR, 2EJN). ${ }^{7}$ These proteins contain four $\alpha$-helical structures and assemble into homo- or hetero-dimers orientated in anti-parallel fashion, held together by covalent disulphide bonds (via one to three conserved Cys residues) and non-covalent interactions. ${ }^{8}$

The uteroglobin (UGB) dimer forms an internal hydrophobic cavity, located at the interface between the two subunits; this is the location of binding of hydrophobic ligands, including steroid hormones, some polychlorinated biphenyl metabolites, retinoids and various eicosanoid mediators of inflammation. ${ }^{9,10}$ UGB's subunits consist of four $\alpha$-helices which do not form a canonical four-helix bundle motif but, rather, a boomerang-shaped structure. The subunits are connected in an antiparallel fashion to form a dimer in which helices 3 and 4 are involved in the dimer interface. In the structure of SCGB1A1, six residues (Phe6, Leu13, Tyr21, Phe28, Met41 and Ile63) in each subunit have been identified as being particularly important to this aspect of UGB structure. ${ }^{11}$ All of these, except Phe28, are accessible to the ligand, which probably functions in maintaining the dimer interface. The other five are involved in ligand binding. The aromatic residues Phe6 and Tyr21 are critical to this binding and cannot be replaced by aliphatic amino acids. Conversely, Leu13 is accessible to solvent in the hydrophobic pocket and is commonly substituted by aromatic amino acids. This suggests that Leu13 may be involved in determining ligand specificity.

\section{Sources of secretoglobin genes and proteins}

Protein sequences for human SCGBs were accessed from Uniprot $^{12}$ through the HUGO Gene Nomenclature Committee website (http://www. genenames.org). Sequences for mouse SCGBs were retrieved from the National Center for Biotechnology Information (NCBI) gene database (http://www.ncbi.nlm.nih.gov/gene), and from the 'supplementary data' of Laukaitis et al. ${ }^{13}$ Sequences were aligned with T-COFFEE using the most accurate mode, which combines multiple sources of sequence homology and structural information, where available. ${ }^{14}$

\section{Human gene family members}

As is commonly the case for a newly discovered family of proteins, SCGBs were originally named based on the location in which they were most highly expressed; this led to the same SCGB often being 'rediscovered' and named multiple times. In 2000, a standard nomenclature was established, when all proteins in the family were named SCGBs 
and assigned family and subfamily names. ${ }^{3}$ The nomenclature system was based on that used for the cytochrome $\mathrm{P} 450^{15,16}$ and nuclear hormone receptor $^{17}$ superfamilies, and was guided by the phylogenetic relationships of known SCGB family members, assembled by $\mathrm{Ni}$ and colleagues. ${ }^{18}$ This provided a convenient and systematic naming system for an entire superfamily. In this report, the most common names used for each protein are listed, along with their standardised names. The human genome contains 11 SCGB genes and five pseudogenes (Figure 1).

\section{SCGB1A1 subfamily}

UGB, also known as blastokinin and CCSP (SCGB1A1), was initially discovered in the rabbit

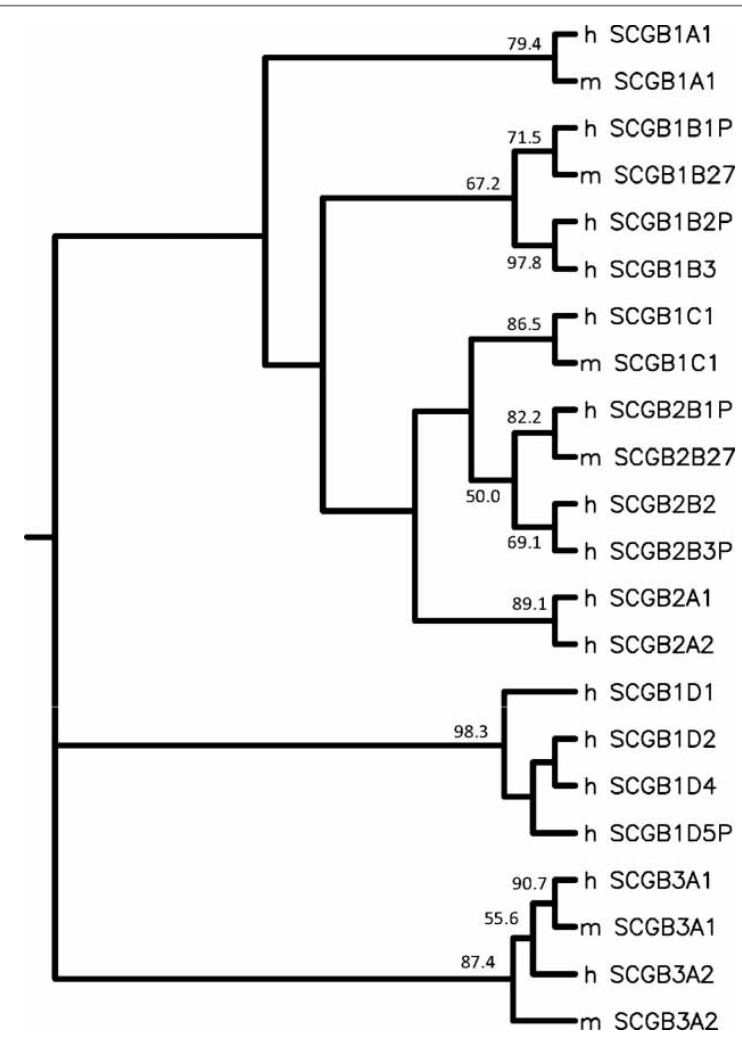

Figure I. Phylogenetic tree of mouse $(\mathrm{m})$ and human $(\mathrm{h})$ SCGBs. For simplicity, and to avoid clutter, of the mouse androgen-binding protein (ABP) group, only SCGBIB27 (ABPA) and SCGB2B27 (ABPGB) are included. SCGB protein sequences were aligned using TCOFFEE ${ }^{14}$ and analysed using nearest-neighbour-joining methods, as well as using 10,000 bootstrap replicates in the Phylip package. ${ }^{19}$ Nodes with $\geq 50$ per cent bootstrap confidence levels have been labelled. uterus and is the founding family member. ${ }^{2}$ For this reason, more information about its biology is available than for many of the other SCGBs. These proteins differ from other SCGBs in that they are homodimers - that is, they are composed of two identical monomers and their subunits lack the middle Cys residue found in other SCGBs. In humans, high SCGB1A1 levels are found in peripheral airway surface fluid, where it is one of the most abundant proteins; it is also expressed in uterine endometrium and the prostate. ${ }^{20}$ In the airways, SCGB1A1 is expressed in several cell types, especially Clara cells, and appears to play a role in immunomodulation through regulation of cell infiltration and in tissue repair after injury. ${ }^{20}$

SCGB1A1 may also exert anti-tumorigenic activity. For example, ablation of the mouse Scgb1a1 gene in some strains is usually lethal and survivors develop tumours. ${ }^{21}$ Conversely, recombinant SCGB1A1 inhibits proliferation and invasion of some cancer cell lines. ${ }^{20}$ Studies of the Scgb1a1 $1^{(-/-)}$knockout mouse suggest that SCGB1A1 may provide protection from oxidative stress and exert anti-inflammatory actions, in addition to providing resistance to pollutant-induced injury. ${ }^{22}$ Interestingly, SCGB1A1 is initially downregulated to allow the body to respond to an infection. ${ }^{23}$

\section{SCGB1B subfamily}

The human genome contains six genes that cluster phylogenetically with genes encoding mouse androgen-binding proteins ( $S c g b 1 b$ and $S c g b 2 b)$. These genes were described based on genomic analysis, and have been given SCGB4A designations. $^{24}$ Based on phylogenetic clustering of their protein sequences, however, we propose that these genes be changed to SCGB1B and SCGB2B designations, to reflect their similarity to the mouse proteins. The $S C G B 1 B$ subfamily includes $S C G B 1 B 1 P$ (formerly $A B P A 1 P$ ), SCGB1B2P (formerly SCGB4A1P) and SCGB1B3 (formerly $S C G B 4 A 4)$. SCGB1B1P and SCGB1B2P are predicted to have become pseudogenes, whereas SCGB1B3 has no obvious inactivating mutations. 
Interestingly, however, SCGB1B2P is the only $S C G B 1 B$ member having evidence for expression in expressed sequence tag (EST) databases.

\section{SCGB1C1}

SCGB1C1 has been shown to be localised to Bowman's glands in the olfactory mucosa. Here, it is thought to act as an odorant-binding protein, with ligands appearing to be small, hydrophobic molecules. $^{25}$

\section{SCGB1D subfamily}

SCGB1D1 and SCGB1D2 are also known as lipophilin A and lipophilin B, respectively. The lipophilins form heterodimers with SCGB2A proteins, which further associate to form tetramers. They have been identified in the prostatic fluid of rats and in the lacrimal gland fluid of humans and rabbits; ${ }^{26}$ little is known about their function.

SCGB1D4 is widely distributed throughout the body; however, expression is particularly strong in the lymph node, tonsil, cultured lymphoblasts and ovary. It is inducible by interferon- $\gamma$ in lymphoblast cells. SCGB1D4 appears to exhibit immunological functions, including regulation of chemotactic migration and invasion. ${ }^{27}$ There is one pseudogene in this subfamily identified as SCGB1D1P1. We propose that it be renamed SCGB1D5P, keeping it in line with the other members of this subfamily.

\section{SCGB2A subfamily}

SCGB2A1 is also known as lipophilin C. SCGB2A2 is also known as mammaglobin and is expressed in a highly tissue-specific manner in breast epithelium, where it forms heterodimers with SCGB1D2. ${ }^{28}$

\section{SCGB2B subfamily}

The $S C G B 2 B$ gene subfamily includes SCGB2B1P (formerly ABPBG1P), SCGB2B2 (formerly SCGB4A2, SCGBL) and SCGB2B3P (formerly $S C G B 4 A 3 P$ ). Of the $S C G B 1 B$ and $S C G B 2 B$ subfamilies, only $S C G B L$ is listed in the HGNC database, but we propose a name change to include it in the SCGB superfamily-naming system. There is only a single reference to SCGB2B2 in the literature ${ }^{24}$ but there is evidence for its expression in EST databases.

\section{SCGB3A subfamily}

SCGB3A1 and SCGB3A2, identified in 2002, have high structural homology ${ }^{29}$ with SCGB1A1. Their expression appears to be localised principally to epithelial organs, such as the lung, mammary gland, trachea, prostate and salivary gland. ${ }^{30}$ In the bronchial epithelium, expression is decreased after injury. $^{29}$ It has been proposed $^{29}$ that SCGB3A1 might have similar and overlapping expression and function with SCGB1A1.

$S C G B 3 A 1$ is a candidate tumour-suppressor gene and a target gene for endothelial PAS domain protein 1 (EPAS1 - formerly HIF2 $\alpha$ ). ${ }^{31}$ SCGB3A1 expression is diminished in many human cancers (including lung, prostate, pancreatic and nasopharyngeal); hypermethylation of the SCGB3A1 promoter has also been reported for many malignancies. ${ }^{31}$ SCGB3A2 has been shown to be induced by T-helper cell 1 (Th1) cytokines but suppressed by proinflammatory and Th2 cytokines. ${ }^{4}$ Any given cytokine can evoke different responses in different SCGBs. ${ }^{4}$ Intranasal administration of recombinant SCGB3A2 suppresses allergen-induced lung inflammation, further highlighting similarities between SCGB3A2 and SCGB1A1. ${ }^{32}$

\section{Mouse gene family members}

\section{Scgb1a1}

This gene encodes mouse UGB and is orthologous to human SCGB1A1.

\section{Scgb1c1}

This gene encodes a protein that is the mouse equivalent of human SCGB1C1.

\section{Scgb1b and Scgb2b: The androgen-binding protein (ABP) family}

Sixty-four of the 68 mouse $\operatorname{Scg} b$ genes belong to a family that has been called the ABP family. ${ }^{13}$ These proteins are heterodimers consisting of two distinct types of subunits, SCGB1B (previously called 
ABPA-like), and SCGB2B (previously ABPBG-like). These were originally isolated from mouse saliva and described based on their ability to bind androgens. ${ }^{33}$ ABPs have since been shown to be expressed in glands of the face and neck, as well as in the prostate and ovary. ${ }^{34}$ The role of ABPs in communication is supported by the expression of many Abpa (Scgb1b) and $A b p b g$ (Scgb2b) mRNAs in the brain (olfactory lobe), sensory organs (olfactory epithelium, vomeronasal organ), glands of the head and neck (parotid, sublingual, submaxillary and lacrimal) and sexual tissues (prostate and ovary and preputial and clitoral glands).

\section{Scgb3a genes}

Scgb3a1 and Scgb3a2 encode predicted proteins that align well with human SCGB3A1 and SCGB3A2 protein structures and are most likely orthologous to them.

\section{Evolution}

SCGB members have amino acid sequences that are highly divergent within the superfamily, complicating the identification of group members. To test whether all entries found were related to known SCGBs, a jackHMMER profile was created (an iterated sequence profile search, seeded with human SCGB1A1), which confirmed group membership for all human and mouse SCGBs ${ }^{35}$ with an expected value of less than 0.001. Homologene, ${ }^{36}$ a software program that analyses groups of homologous proteins across multiple species, currently recognises 21 SCGB clades (Figure 2). The SCGB genes encode proteins that all have a similar structure. ${ }^{18}$ Despite high amino acid sequence divergence, many structural features (such as helical bundles and the ability to dimerise) are retained. ${ }^{11,18}$ This is consistent with a highly flexible and rapidly evolving gene superfamily and is likely to have aided in the evolution of the diverse functions of the superfamily.

When SCGBs were named in 2000, six human SCGBs were described and divided into five groups, based on proposed evolutionary relationships. ${ }^{18}$ Currently, there are 11 described human SCGB genes. Figure 1 shows mouse and human proteins on a phylogenetic tree for this family. In the case of the ABP proteins, we have used SCGB1B27 (ABPA27) and SCGB2B27 (ABPBG27) to represent the mouse SCGB1B and SCGB2B groups, respectively. Table 1 lists chromosomal locations of human SCGBs, and only those mouse genes that share orthology. Four human $S C G B$ s have direct mouse orthologues; the ABP subfamily includes three human $S C G B 1 B$ s versus 30 mouse Scgb1bs and three human SCGB2Bs versus 34 mouse $S c g b 2 b s$. The human genome contains the SCGB1D and SCGB2A subfamilies, both of which are absent in the mouse.

The ABP $(S c g b 1 b / S c g b 2 b)$ family contains genes for two different types of subunit, ABPA (SCGB1B) and $\mathrm{ABPBG}$ (SCGB2B), ${ }^{37}$ located adjacent to each other on mouse chromosome 7 (Table 2). This 'recent, phylogenetically independent proliferation of close paralogs, or lineage specific gene family expansion' is an example of an 'evolutionary bloom'. 37 Another example of this has been most notably studied in the large and diverse cytochrome P450 family. ${ }^{38}$ It has been suggested that these evolutionary blooms might represent simply a stochastic process. ${ }^{37}$

The genes that encode any $S c g b 1 b / S c g b 2 b$ pair tend to be next to each other on the chromosome and orientated in a 'head-to-head' $\left(3^{\prime}-5^{\prime} \mid 5^{\prime}-3^{\prime}\right)$ fashion. These structures have been called 'modules'. 39 It appears that there was a single $S c b g 1 b-S c g b 2 b$ module which has expanded dramatically in some species (64 genes in mouse, 43 in rabbit). In other species it has resulted largely in pseudogenes, such as those of the primate lineage, or been lost altogether in species such as the shrew and elephant. ${ }^{13}$ Interestingly, in humans there are three such modules. Although at least two modules have become pseudogenes, it remains possible that the SCGB1B2-SCGB2B2 module might be active, based on EST data. The mouse shows the most extensive expansion, which began in the ancestor of the genus $M u s^{13}$ after divergence from rat, less than 17 million years ago, and apparently has involved two different modes of duplication. $^{39}$ 


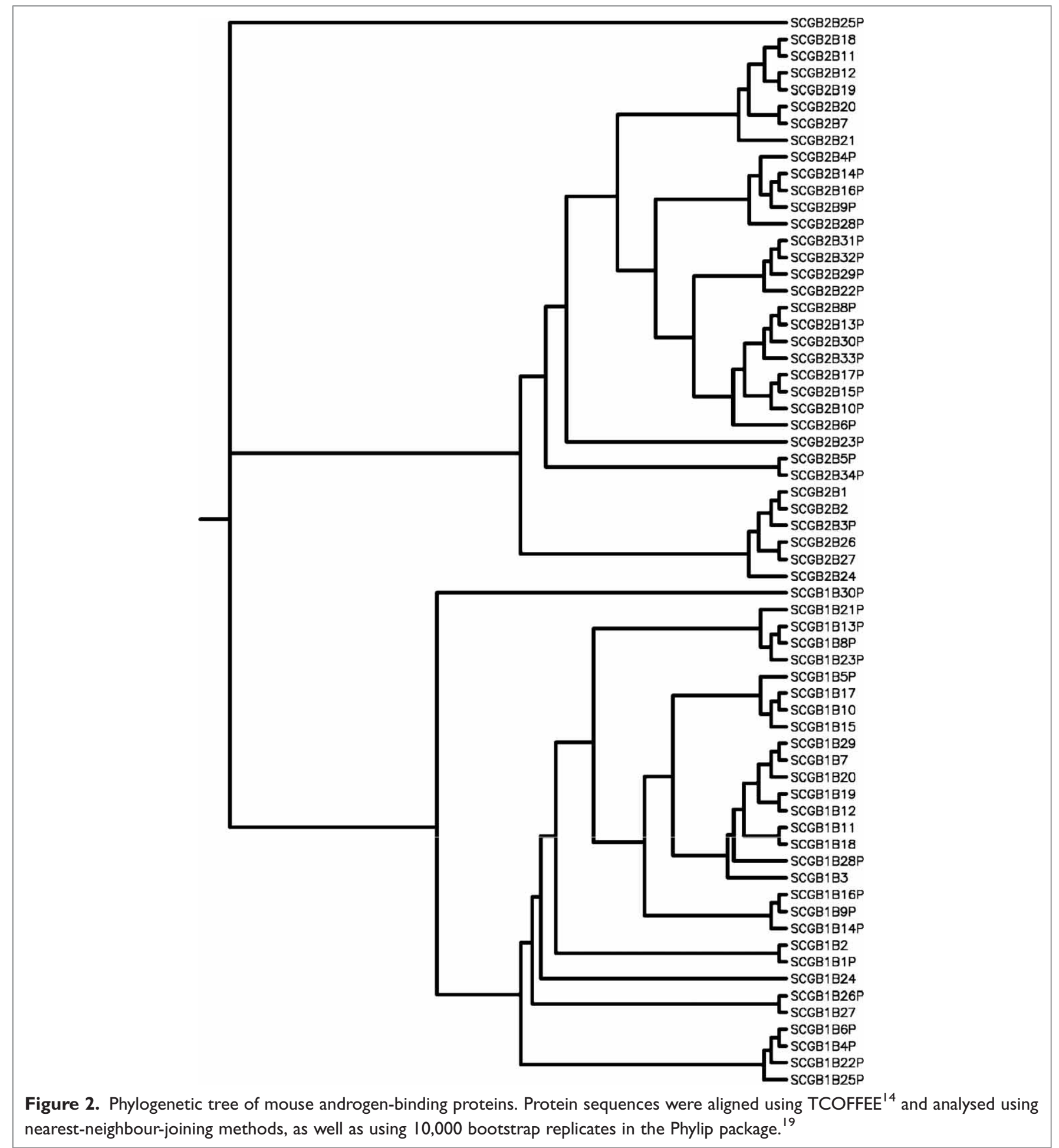

\section{Association of SCGBs with disease}

SCGBs have been linked to multiple disease states, either as participants or as biomarkers. SCGB1A1 may serve as an early biomarker for lung injury, owing to the regenerative role of cells that secrete SCGB1A1. ${ }^{20,40}$ In addition, SCGB1A1 may act as a tumour suppressor ${ }^{41}$ and has been shown to be upor downregulated in various human lung cancers. ${ }^{42}$ 
Table I. Comparison of human secretoglobin genes (SCGBs) with only those mouse Scgbs that share orthology. All data include genes, common names and chromosomal locations. Genes that are likely to share homology are placed on the same line

\begin{tabular}{|c|c|c|c|c|}
\hline Gene symbol & Human chr location & Synonyms & Mouse homologue & Mouse chr location \\
\hline$S C G B I A I$ & IIqII-qter & $\begin{array}{l}\text { Uteroglobin (UGB), blastokinin, Clara-cell specific } \\
\text { I0-kDa protein (CCI0), Clara-cell specific I6-kD } \\
\text { protein (CCI6), Clara-cell specific protein (CCSP), } \\
\text { Clara-cell phospholipid-binding protein (CCPBP), and } \\
\text { urinary protein I (UPI) }\end{array}$ & Scgblal & 19 \\
\hline$S C G B|B| P^{*}$ & 19 & AbpalP & Scgblb subfamily & 7 \\
\hline$S C G B / B 2 P^{*}$ & 19 & SCGB4AIP & & \\
\hline$S C G B / B 3^{*}$ & 19 & SCGB4A4 & & \\
\hline$S C G B / C I$ & IIpI5.5 & RYD5 & Scgblel & 7 \\
\hline SCGBIDI & $1|q| 3$ & Lipophilin A (LIPA) & & \\
\hline SCGBID5P* & $4 q 32.3$ & SCGBIDIPI & & \\
\hline SCGBID2 & ||$q \mid 3$ & Lipophilin B (LIPB) & & \\
\hline SCGBID4 & ||$q \mid 2.3$ & IFN- $\gamma$ inducible SCGB (IIS) & & \\
\hline SCGB2AI & $|I q| 3$ & $\begin{array}{l}\text { Lipophilin C, mammaglobin } 2 \text { (MGB2), mammaglobin B, } \\
\text { UGB3 and lacryglobin }\end{array}$ & & \\
\hline SCGB2A2 & $1|q| 3$ & Mammaglobin I (MGBI), mammaglobin A, UGB2 & & \\
\hline$S C G B 2 B / P^{*}$ & 19 & AbpbgIP & Scgb2b subfamily & 7 \\
\hline SCGB2B2* & 19 & SCGB4A2, SCGBL & & \\
\hline SCGB2B3P* & 19 & SCGB4A3P cytokine high in normal-I (HINI), pneumo & & \\
\hline$S C G B 3 A I$ & $5 q 35$-qter & $\begin{array}{l}\text { Secretory protein } 2 \text { (PnSP-2), and uteroglobin-related } \\
\text { protein } 2 \text { (UGRP2) }\end{array}$ & Scgb3al & 11 \\
\hline$S C G B 3 A 2$ & $5 q 32$ & $\begin{array}{l}\text { Pneumo secretory protein I (PnSP-I), and } \\
\text { uteroglobin-related protein I (UGRPI) }\end{array}$ & Scgb3a2 & 18 \\
\hline
\end{tabular}


Table 2. The mouse androgen-binding protein (ABP) family, complete with the newly proposed Scgb nomenclature. Indicated are the recommended gene symbol, previously published symbol, chromosomal location (Chr), strand, and start and end locations. These data were adapted from Laukaitis et al. ${ }^{13}$ Genomic locations were updated from Build 36 (mm8) of the mouse to Build 37 (mm9) using the University of California, Santa Cruz (UCSC) BLAT tool. Records from the National Center for Biotechnology Information (NCBI) gene database that correspond to mouse ABPs were aligned to these records using TCOFFEE ${ }^{14}$ and analysed using nearest-neighbour-joining methods, as well as using 10,000 bootstrap replicates in the Phylip package; ${ }^{19}$ analogous records are placed on the same line. In some cases, the start and end locations are different from those reported by Laukaitis et al., presumably because of differences in gene prediction algorithms

\begin{tabular}{|c|c|c|c|c|c|c|c|c|c|}
\hline \multirow[t]{2}{*}{$\begin{array}{l}\text { Gene } \\
\text { symbol }\end{array}$} & \multicolumn{3}{|c|}{$\begin{array}{c}\text { Adapted from } \\
\text { Laukaitis }(2008)^{13}\end{array}$} & \multicolumn{2}{|c|}{ Location } & \multicolumn{2}{|c|}{ NCBI record } & \multicolumn{2}{|c|}{ Location } \\
\hline & $\begin{array}{l}\text { Previous } \\
\text { symbol }\end{array}$ & Chr & Strand & Start & End & $\begin{array}{l}\text { Gene } \\
\text { symbol }\end{array}$ & $\begin{array}{c}\text { GI } \\
\text { number }\end{array}$ & Start & End \\
\hline Scgblblp & B6_al $\psi$ & 7 & - & $32,040,110$ & $32,041,296$ & Gm4360 & 100043323 & $32,040,902$ & $32,041,296$ \\
\hline$S c g b 2 b I$ & B6_bgI & 7 & + & $32,048,775$ & $32,050,776$ & & & & \\
\hline Scgb/b2 & B6_a2 & 7 & - & $32,075,661$ & $32,076,819$ & Abph & 57426 & $32,075,538$ & $32,076,835$ \\
\hline$S c g b 2 b 2$ & B6_bg2 & 7 & + & $32,087,800$ & $32,089,833$ & Abpe & 381970 & $32,087,788$ & $32,089,996$ \\
\hline$S c g b 2 b 3 p$ & B6_bg3 $\psi$ & 7 & - & $32,144,059$ & $32,|47,09|$ & Gm4362 & 100043326 & $32,144,057$ & $32,|47,09|$ \\
\hline Scgb/b3 & B6_a3 & 7 & + & $32,160,626$ & $32,|6|, 8||$ & Gm5325 & 384585 & $32,160,617$ & $32,161,935$ \\
\hline$S c g b 2 b 4 p$ & B6_bg44 & 7 & - & $32,186,052$ & $32,188,197$ & & & & \\
\hline$S c g b / b 4 p$ & B6_a44 & 7 & + & $32,194,693$ & $32,195,875$ & & & & \\
\hline Scgb/b28p & B6_a284 & 7 & + & $32,228,841$ & $32,230,016$ & & & & \\
\hline$S c g b 2 b 5 p$ & B6_bg5 $\psi$ & 7 & - & $32,285,202$ & $32,287,735$ & & & & \\
\hline Scgb/b5p & B6_a5 $\psi$ & 7 & + & $32,292,459$ & $32,292,831$ & & & & \\
\hline Scgb2b28p & B6_b28 $\psi$ & 7 & - & $32,330,062$ & $32,331,828$ & & & & \\
\hline Scgb2b6p & B6_bg64 & 7 & - & $32,402,759$ & $32,404,545$ & Gm/9607 & 100503242 & $32,402,757$ & $32,404,545$ \\
\hline Scgb/b6p & B6_a64 & 7 & + & $32,410,618$ & $32,4 \mid I, 808$ & & & & \\
\hline Scgb2b7 & B6_bg7 & 7 & - & $32,488,962$ & $32,490,757$ & Gm4684 & 100043836 & $32,488,798$ & $32,490,772$ \\
\hline Scgb/b7 & B6_a7 & 7 & + & $32,497,700$ & $32,498,874$ & Gm6662 & 626305 & $32,497,690$ & $32,498,998$ \\
\hline Scgb2b8p & B6_bg84 & 7 & - & $32,563,799$ & $32,565,577$ & & & & \\
\hline Scgb/b8p & B6_a8 $\psi$ & 7 & + & $32,573,297$ & $32,574,476$ & & & & \\
\hline Scgb2b9p & B6_bg94 & 7 & - & $32,700,256$ & $32,702,404$ & & & & \\
\hline Scgblb9p & B6_a9 $\psi$ & 7 & + & $32,709,361$ & $32,710,545$ & & & & \\
\hline Scgb2b29p & B6_bg294 & 7 & - & $32,798,052$ & $32,799,818$ & & & & \\
\hline Scgb2b/Op & B6_bg $10 \psi$ & 7 & - & $32,877,166$ & $32,878,958$ & Gm65 /3 & 624584 & $32,877,164$ & $32,878,958$ \\
\hline Scgb/b/0 & B6_al0 & 7 & + & $32,885,887$ & $32,887,066$ & Gm4384 & 100043355 & $32,885,888$ & $32,887,069$ \\
\hline Scgb2bg30p & BG_bg30 $\psi$ & 7 & - & $32,931,261$ & $32,933,051$ & & & & \\
\hline Scgb2b/l & B6_bgII & 7 & - & $32,994,356$ & $32,996,142$ & Gm4687 & 100043842 & $32,994,354$ & $32,996,142$ \\
\hline
\end{tabular}


Table 2. Continued

\begin{tabular}{|c|c|c|c|c|c|c|c|c|c|}
\hline \multirow[t]{2}{*}{$\begin{array}{l}\text { Gene } \\
\text { symbol }\end{array}$} & \multicolumn{3}{|c|}{$\begin{array}{c}\text { Adapted from } \\
\text { Laukaitis (2008) }\end{array}$} & \multicolumn{2}{|c|}{ Location } & \multicolumn{2}{|c|}{ NCBI record } & \multicolumn{2}{|c|}{ Location } \\
\hline & $\begin{array}{l}\text { Previous } \\
\text { symbol }\end{array}$ & Chr & Strand & Start & End & $\begin{array}{l}\text { Gene } \\
\text { symbol }\end{array}$ & $\begin{array}{c}\text { GI } \\
\text { number }\end{array}$ & Start & End \\
\hline Scgb/b/I & B6_all & 7 & + & $33,007,875$ & $33,009,053$ & & & & \\
\hline Scgb2b/2 & B6_bg / 2 & 7 & - & $33,110,463$ & $33,112,248$ & Gm9/38 & 668379 & $33,110,305$ & $33,112,248$ \\
\hline$S c g b / b / 2$ & B6_al2 & 7 & + & $33,119,216$ & $33,120,398$ & Gm9/40 & 668381 & $33,119,217$ & $33,|20,40|$ \\
\hline Scgb/b29 & B6_a29 & 7 & + & $33,226,559$ & $33,227,738$ & Gm5326 & 384589 & $33,226,560$ & $33,227,863$ \\
\hline$S c g b 2 b / 3 p$ & B6_bg I $3 \psi$ & 7 & - & $33,292,522$ & $33,294,299$ & & & & \\
\hline Scgb/b/3p & B6_al34 & 7 & + & $33,302,029$ & $33,303,208$ & & & & \\
\hline$S c g b 2 b / 4 p$ & B6_bg $14 \psi$ & 7 & - & $33,432,671$ & $33,434,820$ & & & & \\
\hline Scgb/b/4p & B6_al4 4 & 7 & + & $33,44 I, 783$ & $33,442,968$ & & & & \\
\hline Scgb2bg3Ip & BG_bg3 $\mid \psi$ & 7 & - & $33,530,315$ & $33,532,081$ & & & & \\
\hline Scgb2b/5p & B6_bg $15 \psi$ & 7 & - & $33,6 \mid 2,867$ & $33,614,659$ & Gm6504 & 624439 & $33,612,702$ & $33,6 \mid 4,672$ \\
\hline Scgb/b/5 & B6_al5 & 7 & + & $33,621,588$ & $33,622,767$ & Gm4399 & 100043376 & $33,621,589$ & $33,622,770$ \\
\hline Scgb2b/6p & B6_bgl64 & 7 & - & $33,659,561$ & $33,661,710$ & & & & \\
\hline Scgb/b/6p & B6_al64 & 7 & + & $33,668,673$ & $33,669,858$ & Gm4404 & 100043383 & $33,668,674$ & $33,669,068$ \\
\hline Scgb2bg32p & BG_bg32 $\psi$ & 7 & - & $33,757,214$ & $33,758,980$ & & & & \\
\hline Scgb2b/7p & B6_bg|7 $\psi$ & 7 & - & $33,839,766$ & $33,841,558$ & Gm9223 & 668526 & $33,839,601$ & $33,84 I, 57 \mid$ \\
\hline Scgb/b/7 & B6_al7 & 7 & + & $33,848,483$ & $33,849,662$ & Gm4406 & 100043388 & $33,848,484$ & $33,849,665$ \\
\hline Scgb2bg33p & BG_bg33 $\psi$ & 7 & - & $33,896,690$ & $33,898,477$ & & & & \\
\hline Scgb2b/8 & B6_bg|8 & 7 & - & $33,957,075$ & $33,958,861$ & Gm4692 & 100043856 & $33,957,073$ & $33,958,86 I$ \\
\hline Scgb/b/8 & B6_al 8 & 7 & + & $33,970,586$ & $33,971,764$ & & & & \\
\hline Scgb2b/9 & B6_bg19 & 7 & - & $34,063,553$ & $34,065,338$ & Gm5894 & 545947 & $34,063,551$ & $34,065,338$ \\
\hline Scgb/b/9 & B6_al9 & 7 & + & $34,072,325$ & $34,073,507$ & Gm5632 & 434676 & $34,072,326$ & $34,073,510$ \\
\hline Scgb2b20 & B6_bg20 & 7 & - & $34,149,526$ & $34,151,319$ & Abpd & 494519 & $34,149,362$ & $34,151,338$ \\
\hline Scgb/b20 & B6_a20 & 7 & + & $34,158,268$ & $34,159,452$ & Gm5895 & 545948 & $34,158,259$ & $34,159,577$ \\
\hline Scgb2bg34p & BG_bg34 $\psi$ & 7 & - & $34,228,045$ & $34,229,836$ & & & & \\
\hline Scgb2b2I & B6_bg2I & 7 & - & $34,303,665$ & $34,305,459$ & Gm6725 & 626970 & $34,303,663$ & $34,305,459$ \\
\hline$S c g b / b 2 / p$ & B6_a2I $\psi$ & 7 & + & $34,3 \mid 2,394$ & $34,3 \mid 3,577$ & & & & \\
\hline Scgb2b22p & B6_bg22 $\psi$ & 7 & - & $34,389,300$ & $34,391,071$ & & & & \\
\hline Scgblb22p & B6_a22 $\psi$ & 7 & + & $34,399,640$ & $34,400,823$ & & & & \\
\hline Scgb2b23p & B6_bg23 $\psi$ & 7 & - & $34,410,332$ & $34,4 \mid 2,120$ & $S c g b 2 b \mid-p s$ & 353109 & $34,410,165$ & $34,4 \mid 2,120$ \\
\hline
\end{tabular}


Table 2. Continued

\begin{tabular}{|c|c|c|c|c|c|c|c|c|c|}
\hline \multirow[t]{2}{*}{$\begin{array}{l}\text { Gene } \\
\text { symbol }\end{array}$} & \multicolumn{3}{|c|}{$\begin{array}{l}\text { Adapted from } \\
\text { Laukaitis }(2008)^{13}\end{array}$} & \multicolumn{2}{|c|}{ Location } & \multicolumn{2}{|c|}{ NCBI record } & \multicolumn{2}{|c|}{ Location } \\
\hline & $\begin{array}{l}\text { Previous } \\
\text { symbol }\end{array}$ & Chr & Strand & Start & End & $\begin{array}{l}\text { Gene } \\
\text { symbol }\end{array}$ & $\begin{array}{c}\text { GI } \\
\text { number }\end{array}$ & Start & End \\
\hline Scgb/b23p & B6_a234 & 7 & + & $34,420,180$ & $34,421,351$ & & & & \\
\hline Scgblb24 & B6_a24 & 7 & + & $34,528,817$ & $34,529,998$ & $\mathrm{Gm} / 2769$ & 100043860 & $34,528,818$ & $34,530,122$ \\
\hline Scgb2b25p & B6_bg254 & 7 & - & $34,638,053$ & $34,639,837$ & $\mathrm{Gm} / 2777$ & 627079 & $34,639,065$ & $34,639,837$ \\
\hline Scgb/b25p & B6_a25 $\psi$ & 7 & + & $34,652,959$ & $34,654,103$ & & & & \\
\hline Scgb2b26 & B6_bg26 & 7 & - & $34,728,187$ & $34,729,983$ & Abpg & 110187 & $34,728,016$ & $34,730,004$ \\
\hline Scgb/b27 & B6_a27 & 7 & + & $34,806,586$ & $34,807,768$ & $A b p a$ & 11354 & $34,806,586$ & $34,807,900$ \\
\hline Scgb/b30p & B6_a30 $\psi$ & 7 & + & $34,880,532$ & $34,885,724$ & $\mathrm{Gm} / 2776$ & 100043868 & $34,880,450$ & $34,885,856$ \\
\hline
\end{tabular}

Proteomic analysis of lacrimal gland fluid has revealed that patients with dry eyes have a decrease in SCGB1D1, SCGB1D2 and SCGB2A1 expression; the condition 'dry eyes' may be caused by posttranslational modifications. ${ }^{43}$ In addition, SCGB1D2 has been reported to be upregulated in breast cancer, making it a potential marker for this type of malignancy. ${ }^{44}$ In this context, panels of autoantibodies to tumour-associated antigens in breast cancer include SCGB1D2, which, when combined with others, may have diagnostic potential. SCGB1D2 is also downregulated in pituitary adenomas. ${ }^{45}$

SCGB2A1 has been shown to be a prognostic marker in epithelial ovarian cancer ${ }^{46,47}$ and endometrial cancer. ${ }^{48}$ Because SCGB2A2 expression is highly specific to breast epithelial tissue, it has been proposed as a marker for detecting breast cancer metastases to sentinel lymph nodes and distant tissues. $^{49-51}$ SCGB2A1 overexpression has also been evaluated as a marker for breast cancer, with mixed conclusions. ${ }^{28,52-55}$

SCGB3A1 has been shown to be differentially expressed in smokers with lung cancer. ${ }^{56}$ Its decreased expression has been correlated with increased tumour burden in non-small-cell lung cancer. $^{31}$ A SCGB3A2 polymorphism has been associated with increased asthma risk in a Japanese population. $^{57,58}$ In chronic rhinosinusitis, SCGB3A2 levels in sino-nasal tissue are inversely correlated with the total number of infiltrating inflammatory cells, as well as scores of symptom severity. ${ }^{4}$

\section{Conclusions}

The SCGBs represent an intriguing family of biologically active proteins. The relatively recent revelations of anti-inflammatory and immunomodulatory functions, together with their potential as cancer biomarkers, underscore their physiological and pathophysiological importance. However, a great deal more needs to be elucidated regarding the actions of individual SCGBs. Further studies directed at characterising the individual SCGBs are necessary, the results of which are likely to yield valuable targets for therapeutic intervention.

One of the most intriguing characteristics of the mammalian 'Abp' genes, the $S c g b 1 b / S c g b 2 b$ subset of the SCGB gene family, is their evolutionarily independent expansions (so-called 'evolutionary blooms') in a number of mammalian lineages. Discovery of the reason for these blooms may lead 
to a better understanding of how these SCGBs function in different mammals.

\section{Acknowledgments}

We thank our colleagues, especially Drs Robert Karn, Christine Laukaitis, Robert Lehrer, Beverly Chilton, Anil Mukherjee, Lucio Miele, Shioko Kimura, Joerg Klug and Richard Emes, for valuable discussions during the course of writing this review and for careful readings of this manuscript. This work was supported by grants NIH F31 AA20728 (B.C.J), NIH NHGRI P41 HG03345 and Wellcome Trust grant O81979/Z/07/Z (M.W.R.), NIH NHGR1 HG 00330 (M.M.), NIH R01 EY017963 (V.K.V) and NIH P30 ES006096 (D.W.N.).

\section{References}

1. Daniel, J.C. (2000), 'Discovery and perspectives from the blastokinin era', Ann. NY Acad. Sci. Vol. 923, pp. 1-8.

2. Beier, H.M. (2000), 'The discovery of uteroglobin and its significance for reproductive biology and endocrinology', Ann. NY Acad. Sci. Vol. 923, pp. 9-24.

3. Klug, J., Beier, H.M., Bernard, A., Chilton, B.S. et al. (2000), 'Uteroglobin/Clara cell 10-kDa family of proteins: Nomenclature committee report', Ann. NY Acad. Sci. Vol. 923, pp. 348-354.

4. Lu, X., Wang, N., Long, X.B., You, X.J. et al. (2011), 'The cytokinedriven regulation of secretoglobins in normal human upper airway and their expression, particularly that of uteroglobin-related protein 1 , in chronic rhinosinusitis', Respir. Res. Vol. 12, p. 28.

5. Pilon, A.L. (2000), 'Rationale for the development of recombinant human CC10 as a therapeutic for inflammatory and fibrotic disease', Ann. NY Acad. Sci. Vol. 923, pp. 280-299.

6. Karn, R.C. and Laukaitis, C.M. (2003), 'Characterization of two forms of mouse salivary androgen-binding protein $(\mathrm{ABP})$ : Implications for evolutionary relationships and ligand-binding function', Biochemistry Vol. 42, pp. $7162-7170$.

7. Berman, H.M., Westbrook, J., Feng, Z., Gilliland, G. et al. (2000), 'The Protein Data Bank', Nucleic Acids Res. Vol. 28, pp. 235-242.

8. Bally, R. and Delettre, J. (1989), 'Structure and refinement of the oxidized P21 form of uteroglobin at 1.64 A resolution', J. Mol. Biol. Vol. 206, pp. $153-170$.

9. Stripp, B.R., Lund, J., Mango, G.W., Doyen, K.C. et al. (1996), 'Clara cell secretory protein: A determinant of $\mathrm{PCB}$ bioaccumulation in mammals', Am. J. Physiol. Vol. 271, pp. L656-L664.

10. Mukherjee, A.B., Zhang, Z. and Chilton, B.S. (2007), 'Uteroglobin: A steroid-inducible immunomodulatory protein that founded the secretoglobin superfamily', Endocr. Rev. Vol. 28, pp. 707-725.

11. Callebaut, I., Poupon, A., Bally, R., Demaret, J.P. et al. (2000), 'The uteroglobin fold', Ann. NY Acad. Sci. Vol. 923, pp. 90-112.

12. UniProt Consortium (2011), 'Ongoing and future developments at the Universal Protein Resource', Nucleic Acids Res. Vol. 39, pp. D214-D219.

13. Laukaitis, C.M., Heger, A., Blakley, T.D., Munclinger, P. et al. (2008), 'Rapid bursts of androgen-binding protein (Abp) gene duplication occurred independently in diverse mammals', BMC Evol. Biol. Vol. 8, p. 46.

14. Notredame, C., Higgins, D.G. and Heringa, J. (2000), 'T-Coffee: A novel method for fast and accurate multiple sequence alignment', J. Mol. Biol. Vol. 302, pp. 205-217.

15. Nebert, D.W. and Nelson, D.R. (1991), 'P450 gene nomenclature based on evolution', Methods Enzymol. Vol. 206, pp. 3-11.
16. Nebert, D.W., Adesnik, M., Coon, M.J., Estabrook, R.W. et al. (1987), 'The P450 gene superfamily: Recommended nomenclature', DNA, Vol. 6, pp. 1-11.

17. Nuclear Receptors Nomenclature Committee (1999), 'A unified nomenclature system for the nuclear receptor superfamily', Cell Vol. 97, pp. 161-163.

18. Ni, J., Kalff-Suske, M., Gentz, R., Schageman, J. et al. (2000), 'All human genes of the uteroglobin family are localized on chromosome 11q12.2 and form a dense cluster', Ann. NY Acad. Sci. Vol. 923, pp. 25-42.

19. Felsenstein, J. (1989), 'PHYLIP - Phylogeny Inference Package (Version 3.2)', Cladistics, Vol. 5, pp. 164-166.

20. Wong, A.P., Keating, A. and Waddell, T.K. (2009), 'Airway regeneration: The role of the Clara cell secretory protein and the cells that express it', Cytotherapy Vol. 11, pp. 676-687.

21. Zhang, Z., Kundu, G.C., Yuan, C.J., Ward, J.M. et al. (1997), 'Severe fibronectin-deposit renal glomerular disease in mice lacking uteroglobin', Science Vol. 276, pp. 1408-1412.

22. Stripp, B.R., Reynolds, S.D., Plopper, C.G., Boe, I.M. et al. (2000), 'Pulmonary phenotype of CCSP/UG deficient mice: A consequence of CCSP deficiency or altered Clara cell function?', Ann. NY Acad. Sci. Vol. 923, pp. 202-209.

23. Hayashida, S., Harrod, K.S. and Whitsett, J.A. (2000), 'Regulation and function of CCSP during pulmonary Pseudomonas aeruginosa infection in vivo', Am. J. Physiol. Lung Cell. Mol. Physiol. Vol. 279, pp. L452-L459.

24. Emes, R.D., Riley, M.C., Laukaitis, C.M., Goodstadt, L. et al. (2004), 'Comparative evolutionary genomics of androgen-binding protein genes', Genome Res. Vol. 14, pp. 1516-1529.

25. Dear, T.N., Boehm, T., Keverne, E.B. and Rabbitts, T.H. (1991), 'Novel genes for potential ligand-binding proteins in subregions of the olfactory mucosa', EMBO J. Vol. 10, pp. 2813-2819.

26. Lehrer, R.I., Nguyen, T., Zhao, C., Ha, C.X. et al. (2000), 'Secretory lipophilins: A tale of two species', Ann. NY Acad. Sci. Vol. 923, pp. $59-67$

27. Choi, M.S., Ray, R., Zhang, Z. and Mukherjee, A.B. (2004), 'IFN-gamma stimulates the expression of a novel secretoglobin that regulates chemotactic cell migration and invasion', J. Immunol. Vol. 172, pp. 4245-4252.

28. Goedegebuure, P.S., Watson, M.A., Viehl, C.T. and Fleming, T.P. (2004), 'Mammaglobin-based strategies for treatment of breast cancer', Curr. Cancer Drug Targets Vol. 4, pp. 531-542.

29. Reynolds, S.D., Reynolds, P.R., Pryhuber, G.S., Finder, J.D. et al. (2002), 'Secretoglobins SCGB3A1 and SCGB3A2 define secretory cell subsets in mouse and human airways', Am. J. Respir. Crit. Care Med. Vol. 166, pp. $1498-1509$.

30. Porter, D., Lahti-Domenici, J., Torres-Arzayus, M., Chin, L. et al (2002), 'Expression of high in normal-1 (HIN-1) and uteroglobin related protein-1 (UGRP-1) in adult and developing tissues', Mech. Dev. Vol. 114, pp. 201-204.

31. Mazumdar, J., Hickey, M.M., Pant, D.K., Durham, A.C. et al. (2010), 'HIF-2alpha deletion promotes Kras-driven lung tumor development', Proc. Natl. Acad. Sci. USA Vol. 107, pp. 14182-14187.

32. Chiba, Y., Kurotani, R., Kusakabe, T., Miura, T. et al. (2006), 'Uteroglobin-related protein 1 expression suppresses allergic airway inflammation in mice', Am. J. Respir. Crit. Care Med. Vol. 173, pp. $958-964$.

33. Dlouhy, S.R. and Karn, R.C. (1983), 'The tissue source and cellular control of the apparent size of androgen binding protein (Abp), a mouse salivary protein whose electrophoretic mobility is under the control of sex-limited saliva pattern (Ssp)', Biochem. Genet. Vol. 21, pp. $1057-1070$.

34. Laukaitis, C.M., Dlouhy, S.R., Emes, R.D., Ponting, C.P. et al. (2005), 'Diverse spatial, temporal, and sexual expression of recently duplicated androgen-binding protein genes in Mus musculus', BMC Evol. Biol. Vol. 5, p. 40

35. Johnson, L.S., Eddy, S.R. and Portugaly, E. (2010), 'Hidden Markov model speed heuristic and iterative HMM search procedure', BMC Bioinformatics Vol. 11, p. 431 
36. Sayers, E.W., Barrett, T., Benson, D.A., Bolton, E. et al. (2010), 'Database resources of the National Center for Biotechnology Information', Nucleic Acids Res. Vol. 38, pp. D5-D16.

37. Waterston, R.H., Lindblad-Toh, K., Birney, E., Rogers, J. et al. (2002), 'Initial sequencing and comparative analysis of the mouse genome', Nature Vol. 420, pp. 520-562.

38. Feyereisen, R. (2011), 'Arthropod CYPomes illustrate the tempo and mode in P450 evolution', Biochim. Biophys. Acta Vol. 1814, pp. 19-28.

39. Karn, R.C. and Laukaitis, C.M. (2009), 'The mechanism of expansion and the volatility it created in three pheromone gene clusters in the mouse (Mus musculus) genome', Genome Biol. Evol. Vol. 1, pp. 494-503.

40. Shijubo, N., Kawabata, I., Sato, N. and Itoh, Y. (2003), 'Clinical aspects of Clara cell 10-kDa protein/uteroglobin (secretoglobin 1A1)', Curr. Pharm. Des. Vol. 9, pp. 1139-1149.

41. Patierno, S.R., Manyak, M.J., Fernandez, P.M., Baker, A. et al. (2002), 'Uteroglobin: A potential novel tumor suppressor and molecular therapeutic for prostate cancer', Clin. Prostate Cancer Vol. 1, pp. 118-124.

42. Sjodin, A., Guo, D., Sorhaug, S., Bjermer, L. et al. (2003), 'Dysregulated secretoglobin expression in human lung cancers', Lung Cancer Vol. 41, pp. $49-56$.

43. Versura, P., Nanni, P., Bavelloni, A., Blalock, W.L. et al. (2010), 'Tear proteomics in evaporative dry eye disease', Eye (Lond.) Vol. 24, pp. 1396-1402.

44. Culleton, J., O’Brien, N., Ryan, B.M., Hill, A.D. et al. (2007), 'Lipophilin B: A gene preferentially expressed in breast tissue and upregulated in breast cancer', Int. J. Cancer Vol. 120, pp. 1087-1092.

45. Sjodin, A., Guo, D., Lund-Johansen, M., Krossnes, B.K. et al. (2005), 'Secretoglobins in the human pituitary: High expression of lipophilin B and its down-regulation in pituitary adenomas', Acta Neuropathol. Vol. 109 , pp. $381-386$.

46. Tassi, R.A., Calza, S., Ravaggi, A., Bignotti, E. et al. (2009), 'Mammaglobin B is an independent prognostic marker in epithelial ovarian cancer and its expression is associated with reduced risk of disease recurrence', BMC Cancer Vol. 9, p. 253.

47. Tassi, R.A., Bignotti, E., Rossi, E., Falchetti, M. et al. (2007), 'Overexpression of mammaglobin B in epithelial ovarian carcinomas', Gynecol. Oncol. Vol. 105, pp. 578-585.
48. Tassi, R.A., Bignotti, E., Falchetti, M., Calza, S. et al. (2008), 'Mammaglobin B expression in human endometrial cancer', Int. J. Gynecol. Cancer Vol. 18, pp. 1090-1096.

49. Janku, F, Kleibl, Z., Novotny, J., Tesarova, P. et al. (2004), 'Mammaglobin A, a novel marker of minimal residual disease in early stages breast cancer', Neoplasma Vol. 51, pp. 204-208.

50. Aihara, T., Fujiwara, Y., Miyake, Y., Okami, J. et al. (2000), 'Mammaglobin B gene as a novel marker for lymph node micrometastasis in patients with abdominal cancers', Cancer Lett. Vol. 150, pp. 79-84.

51. Douglas-Jones, A.G. and Woods, V. (2009), 'Molecular assessment of sentinel lymph node in breast cancer management', Histopathology Vol. 55, pp. 107-113.

52. Zehentner, B.K. and Carter, D. (2004), 'Mammaglobin: A candidate diagnostic marker for breast cancer', Clin. Biochem. Vol. 37, pp. 249-257.

53. Sjodin, A., Ljuslinder, I., Henriksson, R. and Hedman, H. (2008), 'Mammaglobin and lipophilin B expression in breast tumors and their lack of effect on breast cancer cell proliferation', Anticancer Res. Vol. 28, pp. $1493-1498$.

54. Zafrakas, M., Petschke, B., Donner, A., Fritzsche, F. et al. (2006), 'Expression analysis of mammaglobin A (SCGB2A2) and lipophilin B (SCGB1D2) in more than 300 human tumors and matching normal tissues reveals their co-expression in gynecologic malignancies', $B M C$ Cancer, Vol. 6, p. 88.

55. Brown, N.M., Stenzel, T.T., Friedman, P.N., Henslee, J. et al. (2006), 'Evaluation of expression based markers for the detection of breast cancer cells', Breast Cancer Res. Treat. Vol. 97, pp. 41-47.

56. Beane, J., Vick, J., Schembri, F, Anderlind, C. et al. (2011), 'Characterizing the impact of smoking and lung cancer on the airway transcriptome using RNA-Seq', Cancer Prev. Res. (Phila), Vol. 4, pp. 803-817.

57. Inoue, K., Wang, X., Saito, J., Tanino, Y. et al. (2008), 'Plasma UGRP1 levels associate with promoter G-112A polymorphism and the severity of asthma', Allergol. Int. Vol. 57, pp. 57-64.

58. Niimi, T., Munakata, M., Keck-Waggoner, C.L., Popescu, N.C. et al. (2002), 'A polymorphism in the human UGRP1 gene promoter that regulates transcription is associated with an increased risk of asthma', Am. J. Hum. Genet. Vol. 70, pp. 718-725. 